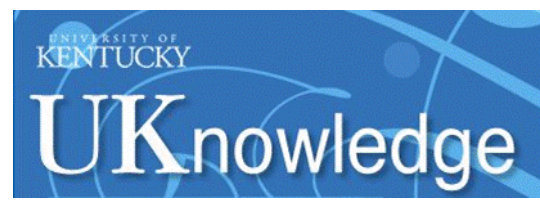

University of Kentucky

UKnowledge

$11-2015$

\title{
Focus Group Evaluation of a Service Leadership Subject in Hong Kong
}

Daniel T. L. Shek

University of Kentucky

Moon Y. M. Law

The Hong Kong Polytechnic University, China

Ting Ting Liu

Wuhan University, China

Follow this and additional works at: https://uknowledge.uky.edu/pediatrics_facpub

Part of the Pediatrics Commons

Right click to open a feedback form in a new tab to let us know how this document benefits you.

\section{Repository Citation}

Shek, Daniel T. L.; Law, Moon Y. M.; and Liu, Ting Ting, "Focus Group Evaluation of a Service Leadership Subject in Hong Kong" (2015). Pediatrics Faculty Publications. 198.

https://uknowledge.uky.edu/pediatrics_facpub/198

This Article is brought to you for free and open access by the Pediatrics at UKnowledge. It has been accepted for inclusion in Pediatrics Faculty Publications by an authorized administrator of UKnowledge. For more information, please contact UKnowledge@lsv.uky.edu. 


\section{Focus Group Evaluation of a Service Leadership Subject in Hong Kong}

Digital Object Identifier (DOI)

https://doi.org/10.1515/ijdhd-2015-0458

\section{Notes/Citation Information}

Published in International Journal on Disability and Human Development, v. 14, no. 4, p. 371-376.

(C) 2015 Walter de Gruyter GmbH, Berlin/Boston

The copyright holders have granted the permission for posting the article here. 
Daniel T.L. Shek*, Moon Y.M. Law and Ting T. Liu

\section{Focus group evaluation of a service leadership subject in Hong Kong}

DOI 10.1515/ijdhd-2015-0458

Received May 20, 2014; accepted July 18, 2014; previously published online September 17, 2015

\begin{abstract}
Two focus groups with six randomly selected students were conducted to understand the views and experiences of students taking a subject entitled "Service Leadership” at The Hong Kong Polytechnic University. Several observations were highlighted from the findings. First, students generally had positive views of the subject. Second, students felt that they had positive experience in the subject. Third, the instructors were seen in a positive light by the students. Fourth, the students perceived the subject to be beneficial to their development. Fifth, students had positive impression about the subject. Finally, recommendations regarding time allocation, teaching style, and classroom environment were expressed by the students.
\end{abstract}

Keywords: evaluation; focus groups; qualitative evaluation; service leadership; university students.

\section{Introduction}

Quantitative evaluation and qualitative evaluation are two main strategies to evaluate social programs, such as

\footnotetext{
*Corresponding author: Daniel T.L. Shek, PhD, FHKPS, BBS, SBS, JP, Associate Vice President (Undergraduate Programme) and Chair Professor of Applied Social Sciences, Department of Applied Social Sciences, The Hong Kong Polytechnic University, Room HJ407, Core H, Hunghom, Hong Kong, P.R. China, E-mail: daniel.shek@polyu.edu.hk; Centre for Innovative Programmes for Adolescents and Families, The Hong Kong Polytechnic University, Hong Kong, P.R. China; Department of Social Work, East China Normal University, Shanghai, P.R. China; Kiang Wu Nursing College of Macau, Macau, P.R. China; Department of Sociology, Wuhan University, Wuhan, P.R. China; and Division of Adolescent Medicine, Kentucky Children's Hospital, University of Kentucky, Lexington, KY, USA

Moon Y.M. Law: Department of Applied Social Sciences, The Hong Kong Polytechnic University, Hong Kong, P.R. China

Ting T. Liu: Department of Sociology, Wuhan University, Wuhan, P.R. China
}

academic subjects and youth programs in social work [1]. Quantitative evaluation approach has the following characteristics. First, numbers and statistics are mainly used (i.e. quantitative data). Second, experimental designs such as clinical trials are commonly employed. Third, treatment groups (groups with intervention) and control groups (groups without intervention) are utilized. Fourth, independent and dependent variables are used. Fifth, hypothetical deductive systems involving hypotheses testing are used to formulate the direction of the study. Sixth, objective outcome evaluation through standardized measures is used. Seventh, in order to maintain neutrality, the evaluator keeps a distance from the program. Eighth, probabilistic and random samples are used so that the data can be generalizable to the population. Ninth, sophisticated statistical analyses focusing on pretest and post-test changes are used. Tenth, standardized and uniform procedures are commonly utilized.

Qualitative research design carries different intrinsic elements. Instead of using numbers and statistics, qualitative evaluation use data such as narratives, documents, and observations. Second, experimental designs such as clinical trials are rarely used. Even if they are used, they will not be regarded as a superior form of evaluation. Third, treatment groups (groups with intervention) and control groups (groups without intervention) are not used under mainstream qualitative research. Fourth, as there is no explicit manipulation of variables, independent and dependent variables are not applicable. Fifth, instead of testing hypotheses derived from hypothetical deductive systems, the researchers undergo inductive processes to generate theory or framework based on the qualitative data collected. Sixth, subjective outcome evaluation by means of open-ended questions and reflections is used to gauge the subjective experience of the program participants. Seventh, in order to understand the reality, the researcher has to keep a close link to the program, such as participant observation. Eighth, purposive or theoretical sampling is commonly used to draw samples in qualitative research. Ninth, statistical analyses are not commonly used in qualitative research. Even if they are used, only simple statistical analyses will be used. Tenth, flexible and creative data collection and analyses methods are utilized [2, 3]. 
Preference for these two evaluation strategies differs from disciplines. Medical science prefers quantitative evaluation while ethnography chooses prolonged observations. In mainstream social sciences, although quantitative evaluation is commonly used to evaluate adolescent prevention and development programs, there is an increase in qualitative evaluation studies [4-6]. For example, in a large-scale positive youth development project in Hong Kong (the Project P.A.T.H.S.), both quantitative and qualitative methods were used to evaluate the program impact $[7,8]$.

Focus groups are commonly used as a qualitative research method in program evaluation. According to Kamberelis and Dimitriadis [9], focus group is a qualitative research method to gauge "people's responses in real space and time in the context of face-to-face interaction" (p. 899). The researcher usually asks focus group participants to express their views of the program, workers, benefits, arrangements, and recommendations for improvement. Using the Project P.A.T.H.S. as an example, focus groups were conducted to understand the views of both the participants and workers. Integrating focus group data collected from different cohorts of students (252 students from 29 focus groups), Shek and Sun [10] found that student reflections and views were mainly positive in nature. Using metaphors as a data collection technique, the participants mainly used positive metaphors to describe the program, instructor, and benefits of the program. Shek [11] also showed similar findings derived from focus groups of program implementers. An integration of focus group findings collected from program implementers (176 participants from 36 focus groups) showed that the views and reflections of the program implementers were generally positive in nature. The program implementers also perceived that the program was beneficial to student holistic development.

This study aims to understand the views of students who took the subject titled "Service Leadership" at The Hong Kong Polytechnic University. According to the Hong Kong Institute of Service Leadership and Management curriculum framework, service leadership is about "satisfying needs by consistently providing quality personal service to everyone one comes into contact with, including one's self, others, communities, systems, and environments" and a service leader is "an on-the-spot entrepreneur who possesses relevant task competencies and is judged by superiors, peers, subordinates, and followers as having character and exhibiting care in action situations" [12, p. 5]. The key formula for service leadership is that effective service leadership is a function of leadership competence and moral code. The service leadership model emphasizes self-leadership and continuous improvement of oneself.

The Hong Kong Polytechnic University developed a two-credit General Education subject Service Leadership to promote service leadership among university students in Hong Kong, and offered to 60 students in 2012-2013 academic year [13]. To evaluate the subject, several tools including objective outcome evaluation, subjective outcome evaluation, and process evaluation were carried out. In this study, qualitative evaluation using the focus group methodology was employed.

\section{Methods}

Two focus group interviews were conducted with 6 students randomly selected from 60 students attending the subject Service Leadership in the second semester of 2012-2013 academic year at The Hong Kong Polytechnic University. The participants were composed of three males and three females from different departments and at different grades.

\section{Procedures}

A registered social worker equipped with qualitative research skills moderated the focus group interview. Prior to the data collection, oral or written consent was obtained from each informant. The social worker discussed with students in a supportive and open manner to understand students' perceptions toward the subject, instructors, and the process. Experienced in group work, the moderator meticulously facilitated each participant to express his/her observation, feelings, comments, and suggestions of both positive and negative nature. The interview was audio-recorded and later transcribed by trained research assistants in an anonymous manner.

\section{Results}

The focus group discussion covered six areas: a) how students perceived the subject; b) how students perceived their learning process in the subject; c) how students perceived the instructor performance; d) what benefits students gained from the subject; e) what students' overall impression of the subject is; and f) what recommendations students would provide for the improvement of the program. Overall, students perceived Service Leadership to be positive in nature and regarded the learning experience as enjoyable and beneficial to their development. The narratives reflecting their perceptions are presented under corresponding themes in the following parts. 


\section{Perceptions of the subject}

Most students thought that the subject was novel in its content and teaching mode. While existing leadership programs mainly focused on training specific task-oriented skills such as "teamwork", "communication”, and "work allocation", this subject was development-oriented which emphasized more on the "long-term" competence building and provided more "theoretical explanations". Students noted that this subject paid more attention to "values and attitudes behind behaviors" and "internal reflections on personal practice”. As one member said:

"In ordinary courses - no matter General Education or other preassigned subjects, we just gained some knowledge after learning, whereas the present subject not only offers knowledge, but also helps to enhance our personal qualities... In my view, it doesn't matter whether you remember many models. The most important point is that you really care and maintain good relationships with others after taking this course. Hence, it is very special to me, which I think is a mind-oriented course".

Besides, students remarked that the teaching style was novel. The "unexpectedly frequent interactions" in this subject, including teacher-student and student-student interactions, deeply impressed them who were even surprised that "a course can be taught and learned in such a mode". As a student shared:

"The major uniqueness of this subject in comparison to others resides in the intensive interactions. If there were no such activities like role-play or drawing, it would be quite boring. Moreover, for those abstract concepts, only through discussions and activities could we comprehend more and better".

For the content, most participants thought it was "clear" and "understandable". All of them thought that more "reflections in connection with practice" and "interactive class activities like role-play" could greatly help them acquire a better understanding of knowledge. As one student shared:

"Actually there is some information we have already known, but the lectures offered plentiful explanations that facilitate our indepth understanding... In other words, sometimes we simply know a thing is good, but this course let us understand why and how it is good. On the other hand, some students felt it isn't easy to digest the information, as there were many 'abstract concepts', 'terms', and 'definitions'”.

Students also highly appreciated the core values and conceptions of service leadership. Some topics and activities in this subject particularly attracted students. According to their sharing, lectures on intrapersonal competences, interpersonal competences, moral character, and Chinese virtues were especially impressive to them because of their "importance to one's life", "stimulation of reflections", or "usefulness for resolving personal problems". Some related narratives include:

- $\quad$ "I agree that good interpersonal relationship is very important... If followers perceive their leader as considerate and empathetic... the work efficiency is naturally enhanced"

- $\quad$ "being caring in the long run is of great importance (to a leader)"

- "we need to learn how to understand ourselves and be aware of our shortcomings; therefore, when working in a team, members can complement each other (to optimize the collective competence)"

\section{Perceptions of the learning experience}

With reference to their learning experience in this subject, the participants unanimously expressed that they enjoyed the process. As one of them commented:

“...whether one enjoys the lectures or not depends on his/her personal attitude. To me, it was enjoyable. We just need to have a bit more commitment and courage to respond to the questions".

Others thought that "this course was relaxing and there was a little urgent assignment. The knowledge covered is useful to our life". In addition, one student said "the information conveyed by the subject is always positive... Even if you are frustrated in other classes, you will cheer up after attending this course". While the degree of student participation varied across groups, many participants felt that their groups were actively participating in class. The following list some student sharing:

- $\quad$ "My group is good. We came from different disciplines, and each member is responsible... Actually the atmosphere was closely related to the performance of group members, some of whom may need some forces to urge them to be responsive".

- $\quad$ "I am so glad that my group mates participated actively. We were highly engaged in every activity”.

Another aspect concerning students learning process is the workload which involved lecture preparation and final assessment, i.e. group presentation and individual paper. Overall, students neither thought the study was difficult nor the workload was heavy. Some related reasons are shown as follows:

- $\quad$ "The atmosphere in the class was free and easy. What students needed to do was basically listening to the lecturers and answering some questions. There were even some games for us to play". 
- $\quad$ "At first I thought a 20-min presentation is very long, but actually time passed quickly. Besides, the topics were not difficult, given the guides offered by instructors. We could resort to our tutors whenever encountering difficulties".

- $\quad$ "If there is a good labor division and trust among members, (it will not be a tough task to prepare the presentation). Members only need to prepare their own parts, and the whole presentation isn't long".

For paper writing, some participants found it challenging. Because they had different majors, they needed more time to search and read relevant literature. Nevertheless, there was a general agreement that the self-reflection part of paper was a little time-consuming and it was necessary to "link what they learned in classroom to real life", which served as a "round-up" of the whole course.

\section{Perceptions of instructors}

When commenting on the instructors of Service Leadership, the point students mentioned most frequently was their commitment to teaching:

- $\quad$ "The three instructors are highly enthusiastic. We feel that they teach with heart and try different ways to communicate with us".

- "I still remember the scene that one instructor shared her own experience in class, whose dedication impressed us and created an atmosphere that encouraged students' engagement and interactions".

Students also reported that instructors adequately prepared the lectures:

- $\quad$ "In the first class, we were surprised when seeing so many materials printed for us... They were highly concerned (about the teaching quality and students) and made great effort to enrich the class, which was reflected in the preparation of course materials".

- A student who seldom received so many materials for a course said, "They prepared really well... I even thought I went to the wrong classroom".

While the instructors were acknowledged for their positive attitude and quality preparation, students indicated problems in instructors' interaction with them. Despite their drawback of teaching skills, students shared a positive view of instructors of this course. Examples of the narratives include:

- $\quad$ "Possibly because they are fresh teachers without enough experience, they may need more experience to improve the methods of enlivening atmosphere and asking questions" and "maybe they give too much positive feedback instead of criticisms, which results in students' taking (the tasks) a bit lightly".

\section{Perceived benefits of the subject}

The students unanimously agreed that the subject benefited them in different aspects. After taking the course, their mindset of leadership was first changed. In the traditional notion, leadership is simply "urging other members or employees to accomplish their tasks well without consideration of their interests", but this subject brought them new conceptions that "caring is very important (to effective leadership)". Another student also pointed out that "instead of aggressive pursuit of predefined goals, building up good relationships is a long-term surviving model", and "leader is not a role fixed for a certain person, but in contrast, it can be taken by any member in a team".

Besides, student "self-confidence" was strengthened after realizing that "everyone can be a leader; everyone can lead a group to finish a task". Furthermore, student emotional competence was improved. A girl who thought she "often had emotional fluctuation" believed that the content of self-leadership was very useful for her to "manage emotion and comforting self". Another participant also said:

"After that course, I learned that... when experiencing adversities or negative emotions, I must remind myself not to be too negative but to apply the strategies recommended in the lectures to cope with the difficulties. It was really helpful!"

Enhancement of interpersonal competence is the third aspect of benefits students mentioned a lot. One even asserted that "how to collaborate with others and how to get along with others" that was emphasized in this subject should be "a compulsory lesson for everybody, especially university students". A participant disclosed that to him "the major help was in dealing with interpersonal relationships", and he "began to consider more the feelings of other people around" after taking this subject. Similar insights can be found in another narrative:

"University students today are quite egocentric, so I think this course can teach them that you are not the only person living in the society, so you need to be empathetic to others. Only through collaborative efforts... can the contribution to the society be maximized".

Finally, the subject was considered beneficial to students' future career development. Here are some of the narratives:

- $\quad$ "I major in nursing, and I think this course can help me in my future jobs, because communication is very important in nursing. After taking Service Leadership, I realized that teammates must have communication, otherwise... the work becomes less meaningful". 
- $\quad$ "I study occupational therapy... which is to help patients return to social lives... I learn that it is not necessary to urge them to do what we suggest... In contrast, we need to care about them, understand them, and provide them support, which is the right way of guiding people".

\section{Overall impression of the subject}

The facilitator asked students to use a metaphor to express their overall impression of the subject. In line with the comments they made, the metaphors were positive in nature which mainly symbolized the usefulness and joy of the course. Specifically, two students reported that the subject was like a "mirror" that allowed them to look at themselves and reflect on "whether I possess (the qualities) or not, how I did before, and whether there is something to be improved". At the same time, a mirror enables them to "observe people around from different angles, which can help to better understand young people and college students today". Another used "chicken soup for the soul" to describe the course, because "it taught a lot of strategies promoting our mental health, which was nutritious for the whole life". Metaphors given by other participants mainly related to the pleasant experience in the course, including "rainbow", "break", and "afternoon tea". Similar to a "rainbow" that has different colors, the Service Leadership class comprised "many people who had different backgrounds and worked together as a whole". One student viewed the course as a "break" that allowed her "to unscramble the thoughts and reflect on the reasons when confronted with spiritual chaos and negative emotions", and then "resume the original work more efficiently". The course was also compared to an "afternoon tea", because "it provided energy but differed from dinner" and "people can eat in a relaxed mood".

\section{Recommendations}

While students' comments on the subject were predominantly positive, recommendations primarily concerning time allocation, teaching style, and classroom environment were proposed as well for the improvement of the program. For teaching, two students suggested extending the time of lecture parts, as they found that "maybe due to too many interactive sections", "there was not enough time left for the explanation of some ideas", and sometimes "the linkage among different parts seemed not so coherent". Another participant who focused on the depth of the course, recommended instructors to raise questions to inspire "more thinking and discussion" and allow students to "show more personal views". Furthermore, the subject needs a heavier emphasis on practice. It would be useful to incorporate "more practical cases" into the lectures to concretely illustrate "in what situations what should be done" according to the theories introduced, and thus students will know not only "something is good", but also "how to practice it". A student even hoped to have a session of community service, because "the practical experience is very different from that of sitting in a classroom and listening to teachers. Even if one writes a good term paper, can he/she perform well in real world settings?" The third recommendation concerns the environment. Students commented that the classroom was too large for this subject, which resulted in "the isolation among groups" and accordingly "the lack of exchange across groups", although "within-group interactions were sufficient". Besides, "people sitting at the back were usually not so responsive", which greatly affected the learning atmosphere. Hence, participants suggested changing the classroom to a smaller one and adopting a denser seating plan, and that instructors should engage more students who are less active.

\section{Discussion}

To promote service leadership in Hong Kong university students, a subject entitled Service Leadership was developed at The Hong Kong Polytechnic University. Using the focus group method, the views and experiences of students taking the course were explored. As the field of service leadership is still at its infancy [13], the present study is a pioneer study examining the subjective experiences of students taking a credit-bearing subject of the field. We hope to use qualitative evaluation data to paint a comprehensive picture of the course effectiveness in helping students to thrive. In the qualitative evaluation literature, focus groups are commonly used to evaluate programs [14-16].

Several observations with respect to the evaluation of the subject could be highlighted from the findings. First, the subject was perceived in a favorable light by the students. Second, the students perceived the learning process to be enjoyable, dynamic, motivating, and beneficial to their learning, Third, although the instructors were less experienced, students appreciated their enthusiasm, adequate preparation, and readiness to engage the students. Fourth, the students thought that the subject benefitted their development in many areas. Fifth, the overall impression of the subject was overwhelmingly positive. 
Finally, some recommendations for improvement were proposed by the students in the focus groups. In short, the qualitative evaluation findings are generally positive, suggesting that the subject was well received by the students and they thought that the subject was beneficial to their development.

Despite the positive evaluation findings of the study, several limitations should be noted. First, as a qualitative evaluation method, focus group methodology inherits the weaknesses of qualitative research, including the inability to generalize the findings to the population. In view of reliability and validity, the findings were subjective and belonged to social constructivist nature of focus group narratives [17].

Moreover, there are alternative explanations for the positive results. First, students may be guided by demand characteristics, and hence playing a "helping role" to fulfill the wishes of the researchers. However, the probability of this explanation was not high because a professional social worker moderated the focus group discussion, who encouraged students to honestly express their views. Second, the favorable picture may be due to the dominant "biased" views in group discussion. However, the social worker conducting the focus group discussion did not observe this phenomenon.

Third, although students who participated in discussion were randomly selected, there is a need to replicate the study to ascertain the possibility of generalizing the results to other contexts. Fourth, because of manpower and time constraints, member checking was not carried out. Fifth, other forms of qualitative research such as weekly diaries [18] could be used to understand student experiences. Despite the mentioned shortcomings, the present findings concur with that of other evaluation studies [19-21] and they provide additional support for the effectiveness of the subject in promoting holistic youth development among Chinese university students in Hong Kong.

Acknowledgments: The Service Leadership research project at The Hong Kong Polytechnic University is financially supported by the Victor and William Fung Foundation.

\section{References}

1. Patton MQ. Utilization-focused evaluation: the new century text. Thousand Oaks, CA: Sage, 1997.
2. Leung JT, Shek DT. Quantitative and qualitative approaches in the study of poverty and adolescent development: separation or integration? Int J Adolesc Med Health 2011;23:115-21.

3. Patton MQ. Qualitative evaluation and research methods. Newbury Park, CA: Sage, 1990.

4. Shek DT, Tang VM, Han XY. Evaluation of evaluation studies using qualitative research methods in the social work literature (1990-2003): evidence that constitutes a wake-up call. Res Soc Work Pract 2005;15:180-94.

5. Patton MQ. Two decades of developments in qualitative inquiry: a personal, experiential perspective. Qual Soc Work 2002;1:261-83.

6. Conners NA, Franklin KK. Using focus groups to evaluate client satisfaction in an alcohol and drug treatment program. J Subst Abuse Treat 2000;18:313-20.

7. Shek DT, Sun RC. The Project P.A.T.H.S. in Hong Kong: development, training, implementation, and evaluation. J Pediatr Adolesc Gynecol 2013;26:S2-9.

8. Shek DT, Sun RC, editors. Development and evaluation of positive adolescent training through holistic social programs (P.A.T.H.S.). Berlin: Springer, 2013.

9. Kamberelis G, Dimitriadis G. Focus groups: strategic articulations of pedagogy, politics, and inquiry. In: Denzin NK, Lincoln YS, editors. The SAGE handbook of qualitative research, 3rd ed. Thousand Oaks, CA: Sage, 2005:887-907.

10. Shek DT, Sun RC. Qualitative evaluation of Project P.A.T.H.S.: an integration of findings based on program participants. ScientificWorldJournal 2012; article ID 528483, 12 pages.

11. Shek DT. Qualitative evaluation of the Project P.A.T.H.S.: an integration of findings based on program implementers. ScientificWorldJournal 2012; article ID 591816, 14 pages.

12. Chung PY. Hong Kong Institution of Service Leadership \& Management (SLAM) curriculum framework. Unpublished manuscript, 2011.

13. Shek DT, Yu L, MA CM, Sun RC, Liu TT. Development of a creditbearing service leadership subject for university students in Hong Kong. Int J Adolesc Med Health 2013;25:353-61.

14. Nabors LA, Weist MD, Tashman NA. Focus groups: a valuable research tool for assessing adolescents' perceptions of schoolbased mental health services. J Gend Cult Health 1999;4:39-48.

15. Nabors LA, Reynolds MW, Weist MD. Qualitative evaluation of a high school mental health program. J Youth Adolesc 2000;29:1-13.

16. Loriz LM, Foster PH. Focus groups: powerful adjuncts for program evaluation. Nurs Forum 2001;36:31-6.

17. Creswell JW. Research designs: qualitative, quantitative, and mixed method approaches. Thousand Oaks, CA: Sage, 2003.

18. Shek DT, Sun RC. Evaluation of the Project P.A.T.H.S. based on students' weekly diaries: findings from eight datasets. ScientificWorldJournal 2012; article ID 354254, 14 pages.

19. Shek DT, Yu L, Ma CM. The students were happy but did they change positively? Yes, they did. Int J Disabil Hum Dev 2014;13:505-11.

20. Shek DT, Lin L, Liu TT, Law YM. Service leadership education for university students in Hong Kong: qualitative evaluation. Int J Disabil Hum Dev 2014;13:523-9.

21. Shek DT, Lin L, Liu TT, Law YM. Process evaluation of a pilot subject on service leadership for university students in Hong Kong. Int J Disabil Hum Dev 2014;13:531-40. 